\title{
Sustainable production process: An application of reliability, availability, and maintainability methodologies in automotive manufacturing
}

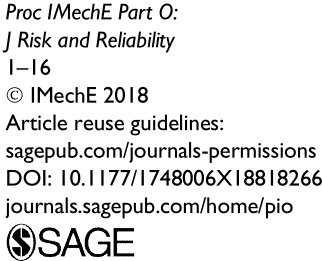

(S)SAGE

\author{
Hamzeh Soltanali',2, A.H.S Garmabaki' (D, Adithya Thaduri', \\ Aditya Parida', Uday Kumar' and Abbas Rohani ${ }^{2}$
}

\begin{abstract}
Automotive manufacturing industries are required to improve their productivity with higher production rates at the lowest cost, less number of unexpected shutdowns, and reliable operation. In order to achieve the above objectives, the application of reliability, availability, and maintainability methodologies can constitute for resilient operation, identifying the bottlenecks of manufacturing process and optimization of maintenance actions. In this article, we propose a framework for reliability, availability, and maintainability evaluation and maintenance optimization to improve the performance of conveying process of vehicle body in an automotive assembly line. The results of reliability, availability, and maintainability analysis showed that the reliability and maintainability of forklift and loading equipment are the main bottlenecks. To find the optimal maintenance intervals of each unit, a multi-attribute utility theory is applied for multi-criteria decision model considering reliability, availability, and costs. Due to the series configuration of conveying process in automotive assembly line, the optimized time intervals are obtained using opportunistic maintenance strategy. The results could be useful to improve operational performance and sustainability of the production process.
\end{abstract}

\section{Keywords}

Automotive manufacturing, conveying process, opportunistic maintenance, reliability, availability, and maintainability methodologies, multi-attribute utility theory

Date received: 8 April 2018; accepted: 24 October 2018

\section{Introduction}

With the current oriented complexity in the automotive industries, the Automotive 4.0 revolution is poised to lead the way for sustainable manufacturing. ${ }^{1,2}$ It provides a framework for human-machine interaction and collaboration to create more value in the future through smart digitalization of production processes. ${ }^{3}$ With the increased automation and digitalization functions, a reliable operation process is one of the major challenges facing the implementation of Automotive 4.0. ${ }^{4,5}$ To ensure a reliable manufacturing process in short or long terms, a systematic analysis of performance, considering all influencing factors, is required. ${ }^{6}$ Performance evaluation plays a substantial role in decision-making process, system optimization procedure and decreasing business risks and uncertainties. ${ }^{7,8}$

In recent decades, the majority of performance evaluation programs such as total productive maintenance (TPM), total quality management (TQM), business continuity management (BCM), business process reengineering (BPR), and so on are proposed to achieve the high productivity and availability in process industries, in particular automotive manufacturing. ${ }^{9,10}$ Along with the successful implementation of these innovative programs, having a resilient operation is inevitable to improve availability and productivity with higher production rate at the lowest cost and less number of unexpected shutdowns.

In such circumstances, the reliability indexes or RAM principle (i.e. reliability, availability and

'Division of Operation and Maintenance Engineering, Luleå University of Technology, Luleå, Sweden

${ }^{2}$ Department of Biosystems Engineering, Ferdowsi University of Mashhad, Mashhad, Iran

Corresponding author:

A.H.S Garmabaki, Division of Operation and Maintenance Engineering, F-Huset, Luleå University of Technology, 97187 Luleå, Sweden.

Email: amir.garmabaki@Itu.se 